\title{
PELATIHAN GURU TAMAN KANAK-KANAK (TK) TENTANG PEMERIKSAAN GIGI SEDERHANA DI TK SEJAHTERA KOTA TASIKMALAYA
}

\author{
Emma Kamelia ${ }^{1}$, Rieza Zulfahmi Taftazani ${ }^{1}$, Anang ${ }^{1}$ \\ ${ }^{1}$ Poltekkes Kemenkes Tasikmalaya \\ *eza.exact@gmail.com
}

\begin{abstract}
School dental health clinic (UKGS) is an effort to improve dental and oral health status. UKGS activities include dental education and dental and mouth examinations. This program is usually carried out by dental health workers in the Community Health Center, but due to the limited number of health workers, this program is not running optimally. In the implementation of UKGS assisted by teachers, teachers are the main key to change the behavior of their students so that the teacher's role is crucial for the success of UKGS. The method of assessing the role of teachers in the success of the UKGS program is by evaluating pre-test and post-test questions about dental and oral health knowledge, the evaluation that can be done to determine teacher skills by filling out a status card. The community service program in 2019 is aimed at Tasikmalaya City Prosperous Kindergarten teachers, where the program aims to improve the teacher's knowledge and skills on oral health so that it can change children's behavior so that their teeth are healthier. The method used is by conducting dental and oral health counseling and providing training in simple dental and oral examination (caries examination). The activity was held in Tasikmalaya City Prosperity Kindergarten, where the activity was carried out by 3 dental health workers assisted by students majoring in dental nursing. Activities carried out for 12 months, which are divided into several activities.
\end{abstract}

Keywords: Kindergarten teacher training, Simple Dental Checkup

\begin{abstract}
ABSTRAK
Usaha kesehatan gigi sekolah (UKGS) merupakan usaha untuk meningkatkan derajat kesehatan gigi dan mulut. Kegiatan UKGS meliputi dental education dan pemeriksaan gigi dan mulut. Program ini biasanya dilakukan oleh tenaga kesehatan gigi yang ada di Puskesmas, tetapi karena terbatasnya tenaga kesehatan maka program ini tidak berjalan maksimal. Dalam pelaksanaannya UKGS dibantu oleh guru, guru merupakan kunci utama untuk merubah tingkah laku anak didiknya sehingga peranan guru tersebut sangat menentukan berhasilnya UKGS. Metode dalam menilai peran guru dalam keberhasilan program UKGS dengan menilai pre test dan post test soal pengetahuan kesehatan gigi dan mulut, evalusi yang dapat dilakukan untuk mengetahui keterampilan guru yaitu dengan mengisi kartu status. Program pengabdian kepada masyarakat tahun 2019 ditujukan kepada guru TK Sejahtera Kota Tasikmalaya, dimana tujuan dari program
\end{abstract}


tersebut diantaranya adalah peningkatan pengetahuan dan keterampilan Guru tentang kesehatan gigi dan mulut sehingga dapat merubah perilaku anak agar giginya lebih sehat. Metode yang digunakan adalah dengan cara melakukan penyuluhan kesehatan gigi dan mulut dan memberikan pelatihan cara pemeriksaan gigi dan mulut sederhana (pemeriksaan karies). Kegiatan dilaksanakan di TK Sejahtera Kota Tasikmalaya, dimana kegiatan dilakukan oleh 3 tenaga kesehatan gigi yang dibantu oleh mahasiswa jurusan keperawatan gigi. Kegiatan dilakukan selama 12 bulan, yang dibagi menjadi beberapa kegiatan.

Kata Kunci : Pelatihan guru Taman Kanak-kanak, Pemeriksaan Gigi Sederhana

\section{PENDAHULUAN}

Usaha Kesehatan Gigi Sekolah (UKGS) adalah bagian integral dari Usaha Kesehatan Sekolah (UKS) melalui pelayanan asuhan kesehatan gigi dan mulut yang diselenggarakan secara terencana, terpadu dan berkesinambungan pada para siswa tingkatan Sekolah Dasar, Taman Kanak-kanak dan PAUD dalam suatu kurun waktu tertentu, melalui paket UKS. Upaya promotif dan preventif paling efektif dilakukan dengan sasaran anak pra sekolah, karena perawatan kesehatan gigi harus dilakukan sejak dini dan dilakukan secara kontinyu agar menjadi suatu kebiasaan (Depkes RI, 2008).

Anak usia pra sekolah (TK) merupakan salah satu kelompok rentan terhadap penyakit gigi dan mulut karena umumnya masih mempunyai perilaku atau kebiasaan diri yang kurang menunjang terhadap kesehatan gigi. Anak usia TK mempunyai ciri khas yaitu sedang menjalani proses tumbuh kembang termasuk tumbuh kembang gigi sulung dan gigi tetap, banyak melakukan aktivitas jasmani, dan mulai aktif berinteraksi dengan lingkungan sosial maupun alam sekitarnya. Gigi pada anak TK umumnya masih merupakan gigi sulung (Primary Teeth) dengan struktur dan morfologi gigi yang rentan terhadap karies. Menurut Maulidta, prevalensi karies gigi anak TK yang masih tinggi disebabkan antara lain karena kebiasaan mereka menyikat gigi tidak sesuai prosedur serta kebiasaan mengkonsumsi makanan yang kariogenik. Selain itu, anak masih sangat tergantung pada orang tua dalam hal menjaga kebersihan dan kesehatan giginya, Untuk mendapatkan hasil yang optimal harus dijaga agar saat masuk sekolah dasar gigi anak tetap bagus (Wirawati, 2008)

Tujuan UKGS tercapainya derajat kesehatan gigi dan mulut siswa yang optimal. Organisasi Kesehatan Dunia (WHO) pada tahun 2007 menyatakan angka kejadian karies gigi pada anak mengalami perlonjakan 60-90\% sedangkan menurut data dari PDGI (Persatuan Dokter Gigi 
Indonesia) menyebutkan bahwa sedikitnya $89 \%$ penderita karies adalah anak-anak. Berdasarkan hasil karakteristik survey kesehatan, prevalensi karies gigi pada balita usia 3-5 tahun sebesar $81,7 \%$. Prevalensi karies gigi menurut kelompok usianya, usia 3 tahun (60\%), usia 4 tahun (85\%) dan usia 5 tahun $(86,4 \%)$, dengan demikian golongan usia TK merupakan golongan rawan terjadinya karies gigi (Suryawati, 2010). Menurut data Depkes RI tahun 2010, prevalensi kesehatan gigi dan mulut di Indonesia terhadap tingkat karies sebesar 70\% dan 50\% diantaranya adalah golongan usia TK (Sariningsih, 2012). Hasil penelitian Suryawati,dkk juga menyebutkan bahwa $76,8 \%$ ibu anak balita memiliki peran yang kurang terhadap kesehatan gigi dan mulut anaknya dan 71,33\% ibu tidak pernah memeriksakan gigi anak balitanya ke dokter gigi karena mereka beranggapan bahwa gigi susu hanya sementara dan akan diganti dengan gigi permanen sehingga ibu menganggap kerusakan pada gigi susu bukan merupakan suatu masalah.3 Berdasarkan observasi yang dilakukan pada 26 murid prasekolah di TK Az-Zahra Gedangan Sidoarjo didapatkan data murid yang memiliki gigi karies sebanyak $76 \%$ sedangkan murid yang tidak memiliki karies sebanyak 24\%, dari data tersebut menunjukkan bahwa angka kejadian karies gigi pada anak usia prasekolah masih tinggi.

Pendekatan ini bisa dengan metode 'Kipas Gigi”. Kipas gigi adalah suatu alat bantu pemeriksaan yang berupa kartu yang disusun seperti kipas dan masing-masing helai mewakili setiap elemen gigi yang cara penggunaannya melibatkan guru pembina UKGS. Penggunaan kipas gigi pada siswa taman kanak-kanak. Oleh karena itu perlunya pelatihan guru pembina UKGS dalam menerapkan metode Kipas gigi kepada anak didiknya sehingga program UKGS dapat berjalan secara maksimal (Gustiana, 2003).

Kegiatan UKGS yang promotif meliputi pelatihan guru dalam kesehatan gigi, penyuluhan kesehatan gigi dan mulut yang dilakukan oleh guru serta kegiatan preventif yaitu sikat gigi massal dengan pasta gigi berfluor. Sedangkan kegiatan kuratifnya meliputi pengobatan darurat untuk menghilangkan rasa sakit serta rujukan bagi yang memerlukan. Tujuan UKGS disini adalah agar siswa TK Sejahtera mempunyai pengetahuan kesehatan gigi dan mulut melalui guru pembina UKGS selain itu meningkatkan derajat kesehatan gigi dan mulut dengan menjalankan usaha promotif dan preventif dirumah (Depkes RI, 1996) 


\section{METODE}

Kegiatan ini dilakukan di TK Sejahtera Perum Tamansari Indah Karsamenak, Kec. Kawalu, Kota Tasikmalaya Prov. Jawa Barat. Pelaksanaan kegiatan dilakukan pada tanggal 23 Agustus-1 Oktober 2019. Kegiatan pelatihan ini diikuti 6 orang guru dan 18 orang siswa. Metode pelaksanaan pada program pengabdian masyarakat ini yaitu dengan upaya pendekatan dari tenaga kesehatan/Dosen kepada Guru TK dengan cara memberikan penyuluhan tentang kesehatan gigi dan mulut dan upaya pendekatan yang dapat dilakukan dengan cara penyuluhan, pelatihan, pendampingan kepada guru TK

Bahan utama yang digunakan dalam kegiatan pengabdian ini adalah alat diagnostic set, tisu, kapas, alcohol, air mineral.

Tahapan pelaksanaan kegiatan sebagai berikut :

1. Tahapan persiapan, yakni sosialisasi tujuan, target, dan luaran program pengabdian kepada kepala sekolah sehingga kegiatan ini mendapat dukungan dan dapat terlaksana dengan baik dan lancar.

2. Tahap pelaksanaan dibagi menjadi 3 tahap yaitu memberikan pelatihan cara pemeriksaan karies gigi

\section{HASIL DAN PEMBAHASAN}

Tahap 1 dengan memberikan pelatihan cara pemeriksaan karies gigi. Kegiatan tersebut dilaksanakan pada Hari Jumat, 23 Agustus 2019 bertempat di TK Sejahter Kota Tasikmalaya. Hasil yang didapatkan berupa output hasil pemeriksaan dari kelompok yang sudah diberikan pelatihan.

Adapun kategori hasil penilaian dapat dikelompokkan menjadi:

1. Nilai $14-20=$ baik

2. Nilai $7-13=$ sedang

3. Nilai $1-6=$ buruk 
Tabel 1. Hasil Pemeriksaan Tahap 1

\begin{tabular}{lllll}
\hline No & $\begin{array}{l}\text { Nama } \\
\text { Guru }\end{array}$ & $\begin{array}{l}\text { Nama } \\
\text { Siswa }\end{array}$ & $\begin{array}{l}\text { Jumlah } \\
\text { gigi }\end{array}$ & $\begin{array}{l}\text { Hasil } \\
\text { penilaian }\end{array}$ \\
\hline 1 & Gita & Alifa & 20 & 5 \\
\hline 2 & Ratih & Ihsan & 20 & 8 \\
\hline 3 & Reny & Naara & 20 & 8 \\
\hline 4 & Dina & Aulia & 20 & 5 \\
\hline 5 & Ema & Jalal & 20 & 8 \\
\hline 6 & Nenden & Razqa & 20 & 10 \\
\hline
\end{tabular}

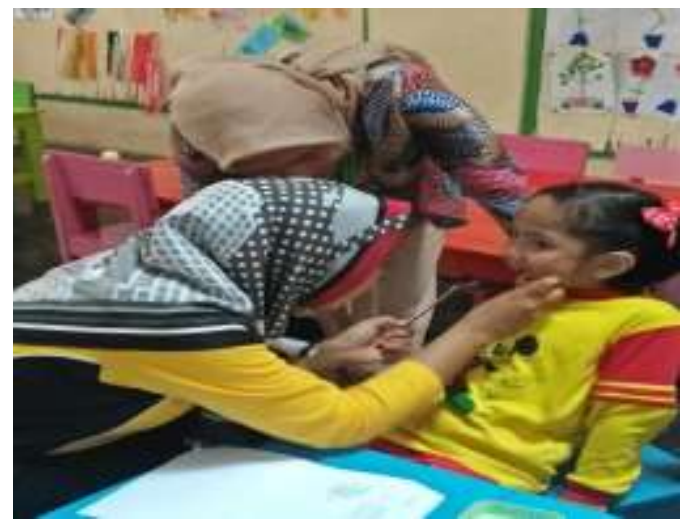

Gambar 1 Pelatihan Pemeriksaan Karies Dini Tahap 1

Pada tahap 2, kegiatan yang dilakukan adalah memberikan pelatihan cara pemeriksaan karies gigi. Hasil yang didapatkan berupa output hasil pemeriksaan dari kelompok yang sudah diberikan pelatihan.

Tabel 2. Hasil Pemeriksaan Tahap 2

\begin{tabular}{lllll}
\hline No & $\begin{array}{l}\text { Nama } \\
\text { Guru }\end{array}$ & $\begin{array}{l}\text { Nama } \\
\text { Siswa }\end{array}$ & $\begin{array}{l}\text { Jumlah } \\
\text { gigi }\end{array}$ & $\begin{array}{l}\text { Hasil } \\
\text { penilaian }\end{array}$ \\
\hline 1 & Gita & Anisa & 20 & 10 \\
\hline 2 & Ratih & Nina & 20 & 12 \\
\hline 3 & Reny & Zahra & 20 & 14 \\
\hline 4 & Dina & Naufal & 20 & 8 \\
\hline 5 & Ema & Risky & 20 & 13 \\
\hline 6 & Nenden & Wildan & 20 & 13 \\
\hline
\end{tabular}




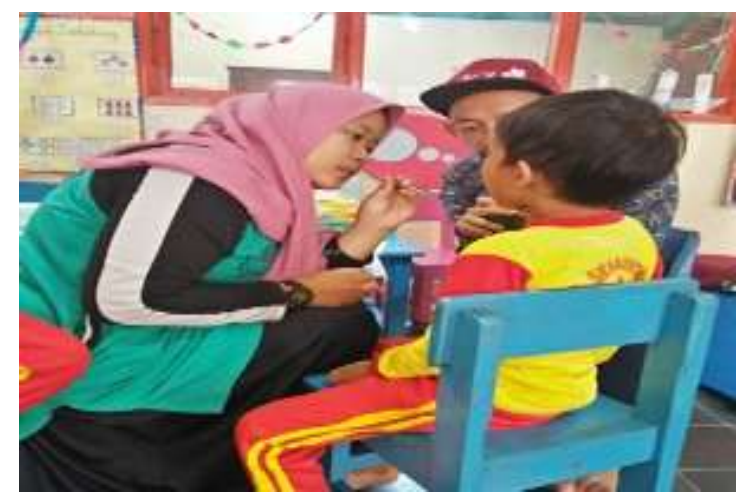

Gambar 2 Pelatihan Pemeriksaan Karies Dini Tahap 2

Selanjutnya tim melakukan kegiatan pengabdian kepada masyarakat tahap 3 yaitu evaluasi pelatihan cara pemeriksaan karies gigi. Kegiatan tersebut dilaksanakan pada Hari Selasa, 1 Oktober 2019 bertempat di TK Sejahtera Kota Tasikmalaya. Hasil yang didapatkan berupa output hasil pemeriksaan dari kelompok yang sudah diberikan pelatihan.

Tabel 3. Hasil Pemeriksaan Tahap 3

\begin{tabular}{c|c|c|c|c}
\hline No & $\begin{array}{c}\text { Nama } \\
\text { Guru }\end{array}$ & $\begin{array}{c}\text { Nama } \\
\text { Siswa }\end{array}$ & $\begin{array}{c}\text { Jumlah } \\
\text { gigi }\end{array}$ & $\begin{array}{c}\text { Hasil } \\
\text { penilaian }\end{array}$ \\
\hline 1 & Gita & Rini & 20 & 16 \\
\hline 2 & Ratih & Nadia & 20 & 17 \\
\hline 3 & Reny & Dani & 20 & 19 \\
\hline 4 & Dina & Father & 20 & 13 \\
\hline 5 & Ema & Fawaz & 20 & 17 \\
\hline 6 & Nenden & yasmin & 20 & 16 \\
\hline
\end{tabular}

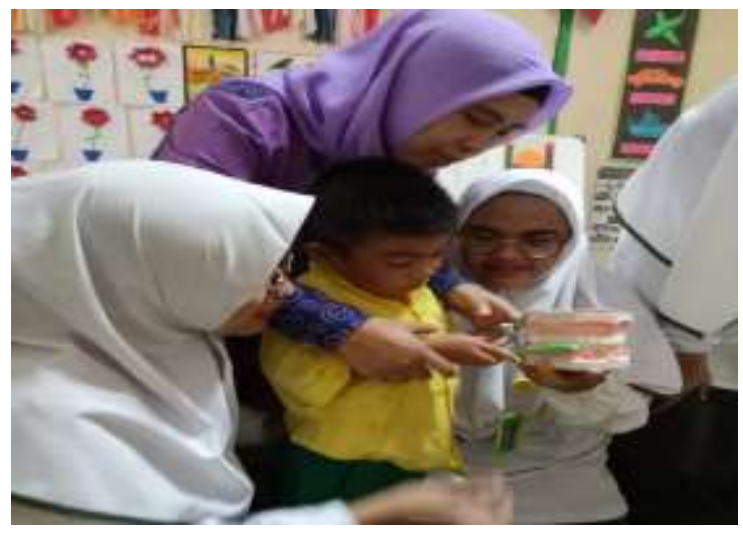

Gambar 3 Pelatihan Pemeriksaan Karies Dini Tahap 3 
Kegiatan pelatihan cara pemeriksaan karies gigi berjalan dengan baik dan efektif. Untuk evaluasi pelatihan pemeriksaan karies gigi yang diberikan kepada guru TK diberikan lembar pemeriksaan.

Produk yang dihasilkan dari kegiatan pengabdian masyarakat ini berupa pelatihan Guru TK Sejahtera Kota Tasikmalaya.

Dari ke tiga tahap tersebut terlihat ada peningkatan dari setiap tahapan, dengan demikian dapat disimpulkan bahwa pelatihan pemeriksaan karies gigi ini dapat dipahami dengan mudah oleh ibu-ibu guru TK. Hasil yang positif ini dapat membantu Puskesmas dalam upaya meningkatkan kesehatan gigi siswa taman kanak-kanak.

\section{Faktor Pendukung dan Kendala}

Hal yang mendukung dari kegiatan pengabdian masyarakat di TK Sejahtera Kota Tasikmalaya dalam pelatihan yaitu guru TK yang aktif kaitannya dengan materi yang disampaikan tersebut sedangkan kendalanya adalah jadwal pelaksanaan yang belum sesuai karena masing-masing dosen dan guru punya kegiatan yang berbeda-beda.

\section{SIMPULAN}

Penyuluhan tentang cara pemeriksaan gigi di TK Sejahtera Kota Tasikmalaya dilakukan beberapa kali kunjungan mengingat materi yang cukup banyak. Guru TK Sejahtera Kota Tasikmalaya memahami bahwa materi yang disampaikan merupakan materi yang penting agar bisa melaksanakan pemeriksaan secara mandiri. TK Sejahtera Kota Tasikmalaya sedang berupaya untuk menata agar kedepannya dapat dilakukan dengan baik. TK Sejahtera Kota Tasikmalaya agar melanjutkan kegiatan pemeriksaan gigi secara mandiri. Pemeriksaan gigi dilakukan secara berkala di TK Sejahtera Kota Tasikmalaya sehingga pada akhirnya tercipta pelayanan yang komprehensif. Para pemangku kepentingan agar dapat mendukung terhadap kesinambungan penyelenggaraan pemeriksaan gigi di TK Sejahtera Kota Tasikmalaya dengan menyediakan dana, sarana, peralatan, dan bimbingan teknis.

\section{UCAPAN TERIMAKASIH}

Terimakasih kepada kepala sekolah dan guru Sejahtera Perum Tamansari Indah Karsamenak, Kec. Kawalu, Kota Tasikmalaya Prov. Jawa Barat 


\section{DAFTAR PUSTAKA}

Depkes RI.(1996). Departemen Kesehatan RI. Pedoman Pelaksanaan Usaha Kesehatan Gigi Sekolah,

Jakarta : Departemen Kesehatan RI.

Depkes RI.(2008). Promosi Kesehatan di Sekolah. Jakarta : Pusat Promosi Kesehatan-Depkes, R.I.

Gustiana, D. (2003). Penggunaan Kipas Gigi pada Siswa Taman Kanak-Kanak. Jakarta: Universitas Indonesia

Sariningsih, Endang. (2012). Merawat Gigi Anak Sejak Usia Dini. Jakarta: Kompas Gramedia

Suryawati, P.N. (2010). 100 Pertanyaan Penting Perawatan Gigi Anak. Jakarta: Dian Rakyat

Wirawati, M.K.(2008). Hubungan Kebiasaan Menggosok Gigi dan Konsumsi Makanan Jajanan Kariogenik dengan Kejadian Karies Gigi Pada Anak Usia Prasekolah di Taman KanakKanak Pondok Beringin Semarang. Semarang: Universitas Diponegoro 